\title{
The intersection of interventional pulmonology and critical care
}

We are honored to present this focused issue of the fournal of Thoracic Disease on the role of interventional pulmonology in the intensive care unit (ICU). To our knowledge, this is the first time a collection of articles has been devoted exclusively to this topic. The impetus for this work was to amalgamate knowledge from the intersection of two dynamic areas of medicinecritical care and interventional pulmonology. The sheer number of articles contained in this issue reflects the tremendous overlap between these two fields. Areas of convergence represent immense potential for multidisciplinary research on subjects largely dominated by anecdotal experience and low-quality data.

Bronchoscopy and airway procedures represent a large portion of the interventional pulmonology that occurs in the ICU. The complementary roles of intensivists and interventional pulmonologists are highlighted in articles that delineate nuances of bronchoscopy in critically ill patients both intubated and non-intubated, novel methods to manage life threatening hemoptysis and foreign body aspiration, utilization of rigid bronchoscopy to alleviate respiratory failure from central airway obstruction, challenges and pitfalls of performing bronchoscopy on patients receiving extracorporeal life support and the evolving role of endobronchial ultrasound in the ICU.

The second part of this collection focuses on the pleural space. Pleural space pathology in critically ill patients is common, and more importantly, the last decade has witnessed a management transition to minimally invasive interventions. The reader is provided with timely reviews and the latest management techniques for pneumothoraces, persistent air leaks, and complex pleural space collections. The expanding role of pleuroscopy and its associated complications in the ICU is highlighted.

The final portion focuses on percutaneous tracheostomy and gastrostomy-key procedures in the ICU. Patient selection, preprocedural evaluation, techniques, and wound care management are systematically addressed in several articles published by experts in the field.

As we weave the ever-growing tapestry of evidence, this collection of manuscripts provides a state-of-the-art review on these dynamic and important subject areas. We hope these will serve as an important resource for both interventional pulmonologists and intensivists when caring for the critically ill patient who requires procedural intervention. The recommendations contained herein are based on data when available and endorsed by leaders in their fields. We welcome feedback from the readers of the Fournal of Thoracic Disease so that we can continue to update and refine manuscripts on this subject matter in the future.

\section{Acknowledgments}

Funding: None.

\section{Footnote}

Provenance and Peer Review: This article was commissioned by the editorial office, Fournal of Thoracic Disease for the series "Interventional Pulmonology in the Intensive Care Unit Environment". The article did not undergo external peer review.

Conflicts of Interest: All authors have completed the ICMJE uniform disclosure form (available at http://dx.doi.org/10.21037/ jtd-2019-ipicu-19). The series "Interventional Pulmonology in the Intensive Care Unit Environment" was commissioned by the editorial office without any funding sponsorship. JSK, AS, \& RN served as the unpaid Guest Editors of the series. Dr. JSK reports personal fees from Level Ex, personal fees from Medtronic, other from Pinnacle Biologics, personal fees from Biodesix, personal fees from American Medical Forum, outside the submitted work. The authors have no other conflicts of interest to declare.

Ethical Statement: The authors are accountable for all aspects of the work in ensuring that questions related to the accuracy or integrity of any part of the work are appropriately investigated and resolved. 
Open Access Statement: This is an Open Access article distributed in accordance with the Creative Commons AttributionNonCommercial-NoDerivs 4.0 International License (CC BY-NC-ND 4.0), which permits the non-commercial replication and distribution of the article with the strict proviso that no changes or edits are made and the original work is properly cited (including links to both the formal publication through the relevant DOI and the license). See: https://creativecommons.org/ licenses/by-nc-nd/4.0/.

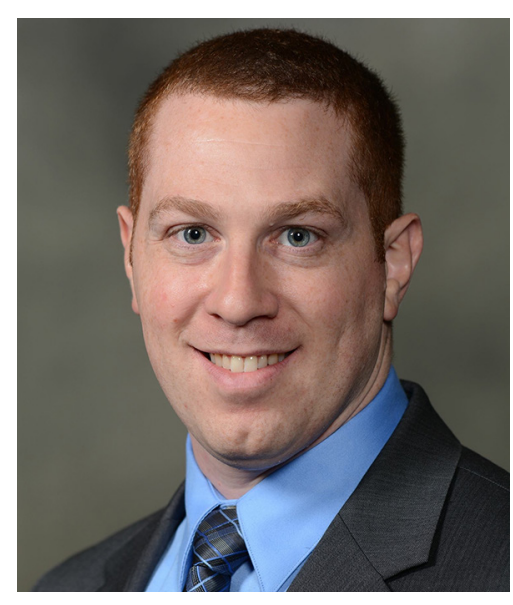

Jonathan S. Kurman

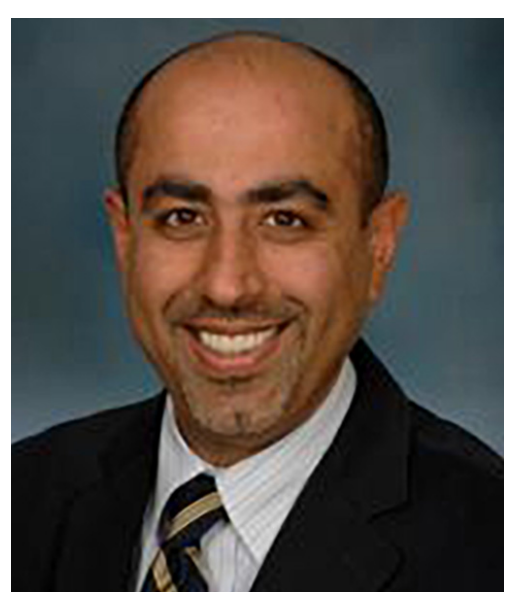

Ashutosh Sachdeva

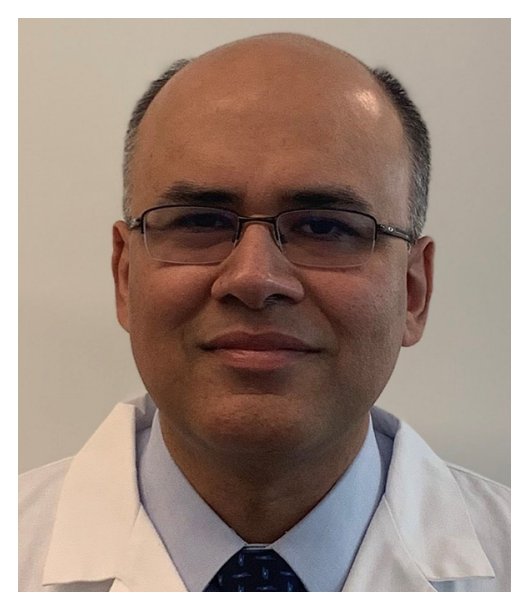

Rahul Nanchal

Jonathan S. Kurman ${ }^{1}$, MD, MBA

(Email:jkurman@mow.edu)

Ashutosh Sachdeva², MBBS

(Email: asachdeva@medicine.umaryland.edu)

Rahul Nanchal ${ }^{1}$, MD

(Email: rnanchal@mow.edu)

${ }^{1}$ Division of Pulmonary \& Critical Care, Medical College of Wisconsin, Milwaukee, WI, USA; ${ }^{2}$ Division of Pulmonary, Critical Care \& Sleep Medicine, University of Maryland, Baltimore, MD, USA.

Submitted Oct 05, 2020. Accepted for publication Oct 29, 2020.

doi: $10.21037 /$ jtd-2019-ipicu-19

View this article at: http://dx.doi.org/10.21037/jtd-2019-ipicu-19

Cite this article as: Kurman JS, Sachdeva A, Nanchal R. The intersection of interventional pulmonology and critical care. J Thorac Dis 2021;13(8):5123-5124. doi: 10.21037/jtd-2019-ipicu-19 